\title{
Role of Striatal Cholinergic Interneurons in Set-Shifting in the Rat
}

\author{
Sho Aoki, $D$ Andrew W. Liu, Aya Zucca, Stefano Zucca, and Jeffery R. Wickens \\ Neurobiology Research Unit, Okinawa Institute of Science and Technology, Onna, Kunigami, Okinawa 904-0495, Japan
}

The ability to change strategies in different contexts is a form of behavioral flexibility that is crucial for adaptive behavior. The striatum has been shown to contribute to certain forms of behavioral flexibility such as reversal learning. Here we report on the contribution of striatal cholinergic interneurons-a key element in the striatal neuronal circuit-to strategy set-shifting in which an attentional shift from one stimulus dimension to another is required. We made lesions of rat cholinergic interneurons in dorsomedial or ventral striatum using a specific immunotoxin and investigated the effects on set-shifting paradigms and on reversal learning. In shifting to a set that required attention to a previously irrelevant cue, lesions of dorsomedial striatum significantly increased the number of perseverative errors. In this condition, the number of never-reinforced errors was significantly decreased in both types of lesions. When shifting to a set that required attention to a novel cue, rats with ventral striatum lesions made more perseverative errors. Neither lesion impaired learning of the initial response strategy nor a subsequent switch to a new strategy when response choice was indicated by a previously relevant cue. Reversal learning was not affected. These results suggest that in set-shifting the striatal cholinergic interneurons play a fundamental role, which is dissociable between dorsomedial and ventral striatum depending on behavioral context. We propose a common mechanism in which cholinergic interneurons inhibit neurons representing the old strategy and enhance plasticity underlying exploration of a new rule.

Key words: behavioral flexibility; cholinergic interneuron; rat; set-shifting; striatum

\section{Introduction}

Behavioral flexibility— the ability to adapt to changes in contingencies, rules, or strategies-is crucial for survival. The prefrontal cortex is considered to be a key brain region in behavioral flexibility, representing the rules governing ongoing tasks. However, to express these rules requires activation of interconnected structures involved in motor outputs (Miller, 2000). The striatum is one such structure and plays an important role in expression of behavioral flexibility. In particular, the dorsomedial striatum is associated with reversal learning (Pisa and Cyr, 1990; Castañé et al., 2010) and set-shifting (Ragozzino et al., 2002b; Nicolle and Baxter, 2003) while the ventral striatum plays a role in learning involving changes in behavioral strategies, or shifting attention to previously irrelevant stimuli (Floresco et al., 2006a). The cholinergic interneurons are a key element in the neuronal circuits of all striatal subregions. Recent studies that have targeted cholinergic interneurons (Brown et al., 2010; Bradfield et al., 2013b; Okada et al., 2014) suggest that they play an important role in the striatal mechanisms of behavioral flexibility.

Received Feb. 5, 2015; revised May 1, 2015; accepted May 16, 2015.

Author contributions: S.A. and J.R.W. designed research; S.A., A.W.L., A.Z., and S.Z. performed research; S.A. and J.R.W. analyzed data; S.A. and J.R.W. wrote the paper.

This study was supported by Human Frontier Science Program and the Sasakawa Scientific Research Grant from the Japan Science Society.

The authors declare no competing financial interests.

Correspondence should be addressed to either Sho Aoki or Jeffery R. Wickens, Neurobiology Research Unit, Okinawa Institute of Science and Technology, 1919-1 Tancha, Onna, Kunigami, Okinawa 904-0495, Japan. E-mail: sho.aoki@oist.jp or wickens@oist.jp.

DOI:10.1523/JNEUROSCI.0490-15.2015

Copyright $\odot 2015$ the authors $\quad 0270-6474 / 15 / 359424-08 \$ 15.00 / 0$
Tonically active striatal neurons that are presumed to be cholinergic interneurons acquire responses to sensory stimuli after they have been repeatedly paired with reward (Kimura et al., 1984; Aosaki et al., 1994, 1995; Graybiel et al., 1994). Acquisition of these responses is dopamine dependent (Aosaki et al., 1994), but the neurons do not simply mirror the activity of dopamine neurons (Morris et al., 2004). More recent studies (for review, see Apicella, 2007) suggest that cholinergic interneurons also respond to spatial attributes such as the location of a stimulus or movement direction (Ravel et al., 2006) and the behavioral context (Lee et al., 2006). These findings suggest that cholinergic interneurons are involved in flexible switching of responses to directional cues in different contexts.

Consistent with electrophysiological findings, cholinergic interneurons and their thalamic afferents have been implicated in behavioral flexibility. Brown et al. (2010) showed that inactivation of the thalamic afferents to cholinergic interneurons did not affect place learning in a cross maze, but impaired learning when the rewarded side was switched. The impairment was failure to maintain new correct choice patterns (regressive errors). Similarly, Bradfield et al. (2013b) found that loss of afferents from the parafascicular nucleus, which reduced cholinergic cell activity, impaired goal-directed learning but only after changes in the action-outcome contingency. In contrast, Okada et al. (2014) found that specific lesions of cholinergic interneurons caused enhanced reversal of a spatial discrimination task.

We investigated the hypothesis that cholinergic interneurons are involved in flexible switching of responses to directional cues using a strategy set-shifting task (Floresco et al., 2008) involving different types of attention, and reversals. We compared intact 
A

Condition 1 (initially no light)

Response strategy ( 4 days, Phase 1 )

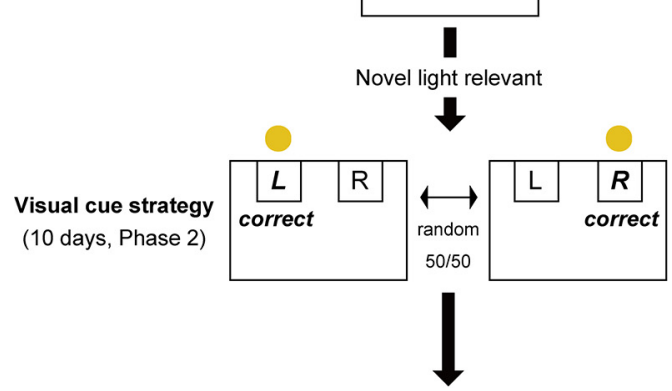

Retraining Response strategy ( 3 days, Phase 3 )

\section{Reversal}

Response strategy

( 3 days, Phase 4 )
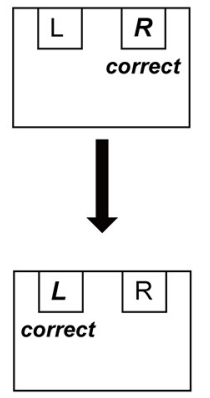

B

Condition 2 (initially light relevant)

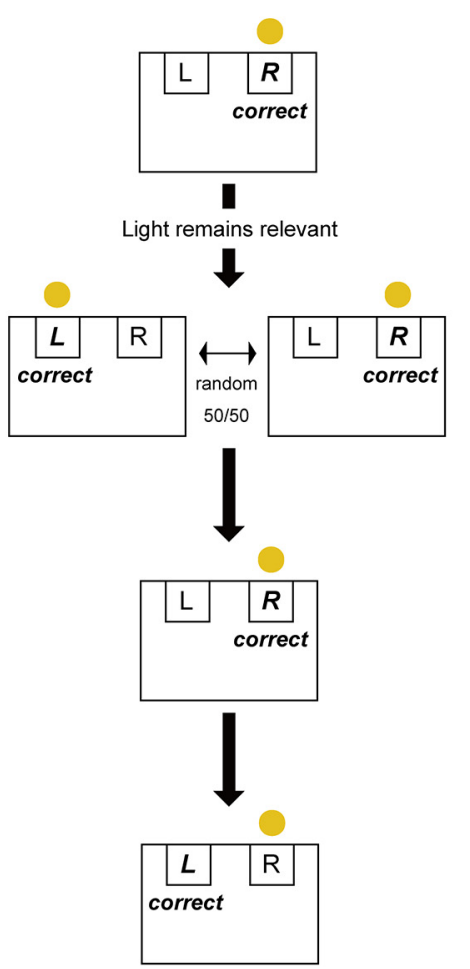

C

Condition 3 (initially light irrelevant)

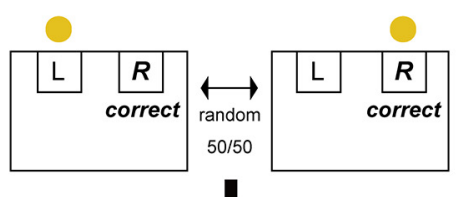

Light becomes relevant
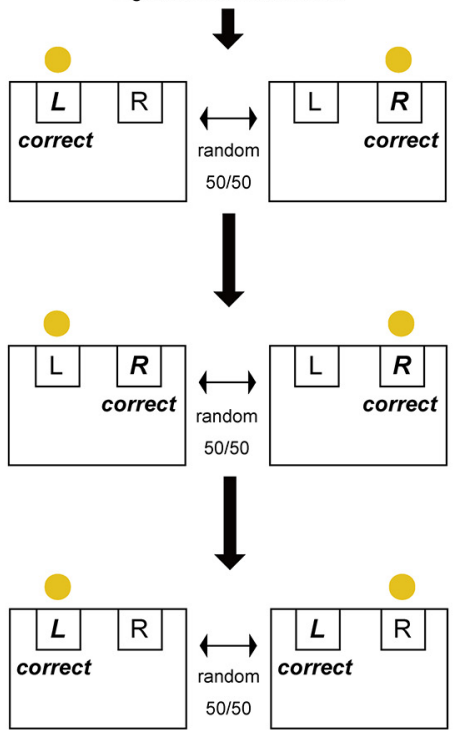

Figure 1. A flow chart of the behavioral paradigms. A yellow circle indicates a visual cue. In set-shifting, three different experimental conditions require animals to attend to a novel cue ( $\boldsymbol{A}$, Condition 1 ), to a previously relevant cue ( $\boldsymbol{B}$, Condition 2), or to a previously irrelevant cue ( $\boldsymbol{C}$, Condition 3 ).

rats with rats in which immunotoxin-induced specific lesions of cholinergic interneurons were made in dorsomedial or ventral striatum. In support of the hypothesis, we found dissociable effects of cholinergic lesions of dorsomedial or ventral striatum on set-shifting.

\section{Materials and Methods}

Ethical approval

All procedures involving animals were approved by the Committee for Care and Use of Animals at Okinawa Institute of Science and Technology.

\section{Animals and groups}

Male Long-Evans rats weighing 250-300 g on arrival were used in a series of experiments. All animals were provided with food and water ad libitum and housed under standard conditions ( $12 \mathrm{~h}$ light/dark cycle, at $23^{\circ} \mathrm{C}$ ) until $5 \mathrm{~d}$ before behavioral experiments. Thereafter animals were food restricted to $\sim 85 \%$ of their average weight. Animals were tested in three experimental conditions detailed below (Fig. 1). Three groups of animals were compared: control, dorsomedial striatum lesion (DMS), and ventral striatum lesion (VS).

\section{Surgical procedures}

Stereotaxic surgery was conducted under isoflurane anesthesia (initial, 3.5\%; maintenance, $2.5-3 \%$ ). In lesion groups, we injected anti-choline acetyltransferase saporin (Advanced Targeting Systems) to induce specific lesions of cholinergic interneurons while leaving other types of cells intact (Laplante et al., 2011). The agent was pressure injected bilaterally in either DMS or VS. Control groups were injected with saline in either DMS or VS in a counterbalanced manner. Coordinates of injection sites were as follows: from bregma or dural surface: DMS: AP $+1.0 \mathrm{~mm}, \mathrm{ML}$ $2.0 \mathrm{~mm}$, and depth $3.7 \mathrm{~mm}$; VS: AP $+1.6 \mathrm{~mm}$, ML $1.9 \mathrm{~mm}$, and depth 6.6 $\mathrm{mm}$. The injection volume for lesions and controls was $0.5 \mu \mathrm{l}$ for DMS and $0.45 \mu \mathrm{l}$ for VS in each hemisphere. After recovery, behavioral experiments were commenced.

\section{Behavioral procedure and analysis}

Habituation and conditioning. After recovery from surgery, animals were habituated to an operant chamber (Med Associates). After magazine training, animals completed a continuous reinforcement schedule to learn to press a lever for a food reward (a sucrose pellet, $45 \mathrm{mg}$; TestDiet), until 60 pellets had been obtained (60 lever presses) or $40 \mathrm{~min}$ had passed. Next, lever-press training was performed for five to eight sessions under the same trial schedule as testing procedures mentioned below. In leverpress training, the left or right lever was inserted randomly and animals were required to press the lever within $10 \mathrm{~s}$ of lever insertion. Finally, side bias was tested to see the animal's preference for left or right lever (Floresco et al., 2008).

Trials. A trial was commenced with a $3 \mathrm{~s}$ tone. Two seconds after the tone ceased, two levers were presented and animals were allowed to choose either the left or right lever within $10 \mathrm{~s}$. During lever-press training, only one lever was presented. If there was no response within $10 \mathrm{~s}$, both levers were retracted and the trial was counted as an omission. In some conditions there was a light stimulus above a lever, which was turned on immediately after the termination of tone and turned off when animals pressed a lever or in $10 \mathrm{~s}$ after lever insertion when omissions.

Testing procedures. A daily session was composed of 80 trials with intertrial intervals of $20-30 \mathrm{~s}$. Figure 1 shows the testing procedure. Phase 1 comprised four consecutive sessions. In all conditions a response strategy was required in which animals learned to press a lever based on lever location. The correct side was opposite to their preference based on the side-bias test. Phase 2 comprised 10 sessions. In all conditions a visual cue strategy was required in which the correct lever was indicated by an illuminated light. Three different conditions of attentional shifts were compared. In condition 1 (Fig. 1A) no light was shown in phase 1, but in phase 2 a light indicated the correct lever. Animals in condition 1 thus had to attend to a novel visual cue. In condition 2 (Fig. 1B) a light stimulus was shown above the correct lever in phase 1 , and again in phase 2. In this condition the visual cue had been relevant, but not necessarily used in making the choice in phase 1 . In condition 3 (Fig. 1C) the light 
stimulus was randomly presented above either the left or right lever in phase 1 ; in phase 2 animals had to pay attention to the light stimulus that was previously irrelevant. After completing this set-shifting paradigm (phases 1 and 2), animals entered phase 3 in which they were retrained in the initial response strategy for 3 sessions and then tested in reversal learning as phase 4 , where they had to respond to the previously incorrect side (Fig. 1).

Data analyses. Percentage of correct responses in each daily session was measured in all conditions, excluding omission trials. During learning of a visual cue strategy (Fig. 1, phase 2), accumulated errors over 10 sessions were counted and classified as perseverative, regressive, or neverreinforced errors (Floresco et al., 2008). Perseverative errors were defined as incorrect responses made on the previously correct lever while the level of performance was still significantly below chance (Jones and Mishkin, 1972; Dias et al., 1996, 1997; Hunt and Aggleton, 1998; Dias and Aggleton, 2000). Various, but conceptually similar, criteria for the perseverative error have been used in the past (Ragozzino et al., 2002b; Floresco et al., 2006a, b, 2008). Using a principled approach, we defined the criterion for perseveration as the point at which the animal began scoring fewer than 8 of 10 incorrect responses (probability of scoring 8/10 errors or more $=0.054$, cumulative binomial distribution) in a moving window of 10 trials. To determine this point, we started the 10 trial window from first trial and then advanced it by one trial at a time until fewer than eight errors out of 10 trials were counted. Subsequent errors made after the same point were counted as regressive. We performed this analysis across all trials where a light cue was on the previously incorrect side during visual cue learning. Never-reinforced errors were counted when animals pressed the previously incorrect lever above which the light was not illuminated. Those errors were subdivided into an early or late component; errors that occurred in the first half of visual cue learning (sessions $1-5$ ) were regarded as early and those in the second half (sessions 6-10) were considered late.

For error analysis of reversal learning, we used the same criterion as in the set-shifting. Again, we counted number of errors in a moving window of 10 trials and advanced the window by one trial until fewer than eight errors out of 10 trials were scored. Errors before this point were regarded as perseverative errors. Once the score became $<8 / 10$ incorrect responses, subsequent errors were counted as regressive errors.

\section{Histology}

After the completion of behavioral experiments, the animals were perfused with $4 \%$ paraformaldehyde. Brains were extracted and postfixed in the same fixative. We prepared coronal sections $(60 \mu \mathrm{m})$ using a vibratome (VT1000S; Leica) and divided sections into four vials. Choline acetyltransferase (ChAT) and nuclei (NeuN) immunohistochemistry were performed in one or two of four vials. For ChAT staining, briefly, sections were incubated overnight in a polyclonal anti-ChAT antibody raised in goat (AB144P; Millipore) and later incubated in rabbit anti-goat IgG-conjugated biotin secondary (Sigma). NeuN staining was performed by Fox3 primary antibody (AB104224; Abcam) and a secondary antimouse IgG-conjugated biotin (Invitrogen). Both ChAT and NeuN signals were enhanced by an avidin-biotin complex method (ABC Elite; Vector Laboratories) and visualized using a metal-enhanced DAB Substrate Kit (\#34065; Thermo Scientific). Lesioned extent in each animal was examined by ChAT staining under a light microscope (CX22; Olympus). Images of representative sections (Fig. 2) were photographed using a digital microscope (BZ-9000; Keyence). To indicate the range of lesion extent the smallest and largest lesions in each treatment group were drawn for all the experimental conditions (Fig. 2; Paxinos and Watson, 2004).

\section{Statistical analysis}

All analyses were conducted with SPSS Statistics version 21. Percentage of correct responses in a series of behavioral tasks was analyzed using a two-way ANOVA for repeated measures with treatment as a betweensubjects factor. Analysis of errors was performed using a one-way ANOVA with treatment as the between-subjects factor followed by Dunnett's test for multiple comparisons. Before ANOVAs, when a Levene's test for homogeneity of variance indicated unequal variance, a more conservative Welch's ANOVA followed by Dunnett's T3 test was applied. For the number of perseverative errors in set-shifting (Phase 2) in conditions 1 and 2 where a violation of the normality assumption of ANOVA was obvious, analysis was performed using the equivalent nonparametric Kruskal-Wallis test followed by Dunn's test with the Bonferroni correction for pairwise comparisons. A difference of $p<0.05$ was considered significant.

\section{Results}

Immunotoxin injections caused specific lesions of the cholinergic interneurons (Fig. 2A), consistent with a previous study using the same immunotoxin (Laplante et al., 2011). Small nonspecific lesions were seen in some sections close to the injection site (Fig. $2 B)$. Since the nonspecific lesions were much smaller than the extent of the associated cholinergic lesion, we included them into later analyses. The extent of the lesions was similar between conditions, as illustrated by comparisons of the smallest and largest lesion cases in each group (Fig. 2C,D). Note that DMS lesions included mostly anterior DMS and a part of posterior DMS (Fig. 2C; compared with Bradfield et al. (2013b), and that VS lesions affected both core and shell subdivisions (Fig. 2D).

Across all the three experimental conditions, initial learning of the response strategy was not affected by either DMS or VS lesion (Fig. $3 A-C$; in all conditions: $F<2.4, p>0.05$ ), suggesting that lesions of cholinergic interneurons did not affect acquisition of the initial strategy.

When switching a strategy in condition 1, where a novel stimulus was introduced as a new directional cue, a percentage of correct responses in rats with lesions of cholinergic interneurons in VS seemed lower but not significant (Fig. $3 A$; treatment effect: $F_{(2,46)}=0.120, p=0.887$; time-by-treatment interaction: $F_{(18,414)}$ $=1.327, p=0.234)$. However, analysis of each class of error indicated that the number of perseverative errors was significantly different between groups (Fig. 3A; Kruskal-Wallis test, $\left.\chi^{2}(2)=6.292, p=0.043\right)$. Multiple comparisons showed a significant increase of perseverative errors in VS lesions (Dunn's test, VS vs control: $p=0.037$; DMS vs control: $p>0.05)$. In contrast, there were no differences in the numbers of regressive errors, never-reinforced errors, nor their subdivided early and late components (Fig. $3 A$; one-way ANOVAs, $F_{(2,46)}<1, p>$ $0.05)$.

During strategy set-shifting in condition 2 where animals were required to shift their attention to a previously relevant cue, neither lesion had an effect on the learning performance (Fig. 3B; treatment effect: $F_{(2,42)}=0.092, p=0.912$; time-by-treatment interaction: $\left.F_{(18,378)}=1.209, p=0.291\right)$. Separate error analyses showed no effects on the number of each error type (Fig. 3B; Kruskal-Wallis test for the perseverative error, $\chi^{2}(2)<1.4, p>$ 0.05 ; one-way ANOVAs for the other types of errors, $F_{(2,42)}<2.6$, $p>0.05)$.

When attention to a previously irrelevant stimulus was required to switch a behavioral strategy in condition 3 (Fig. 3C), the percentage of correct responses showed slightly slow increment in DMS lesions in the middle of learning, but it was not significant (Fig. $3 C$; treatment effect: $F_{(2,51)}=0.530, p=0.592$; timeby-treatment interaction: $\left.F_{(18,459)}=1.395, p=0.222\right)$. Importantly, however, error types were clearly changed after cholinergic interneuronal lesions in that the number of perseverative errors was significantly different (Fig. 3C; Welch's ANOVA, $\left.F_{(2,28.128)}=6.315, p=0.005\right)$. Multiple comparisons with the control indicated a significant increase of the perseverative errors in DMS lesions (Dunnett's T3, $p=0.007$ ) but not in VS lesions $(p>0.05)$. In contrast, there was no effect on regressive errors 

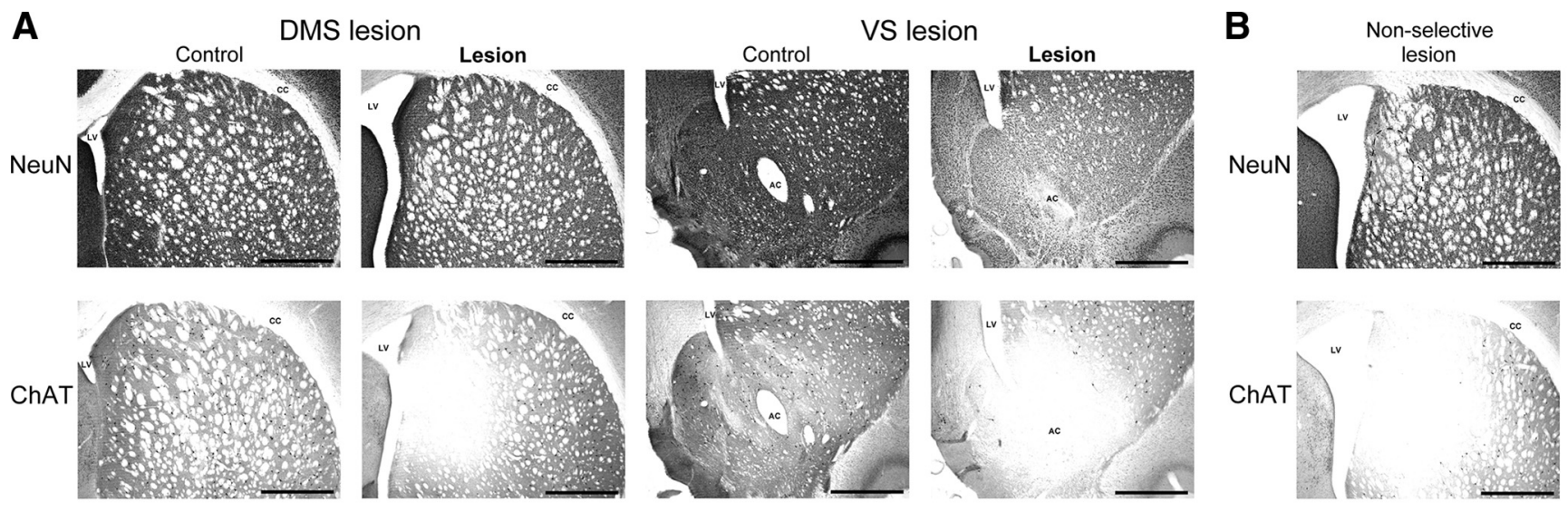

C

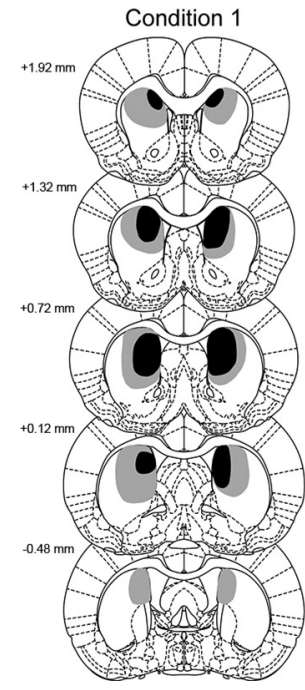

DMS lesion

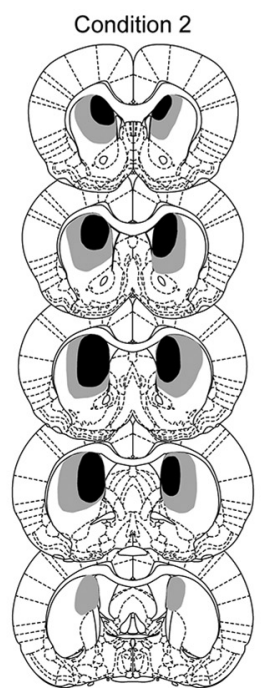

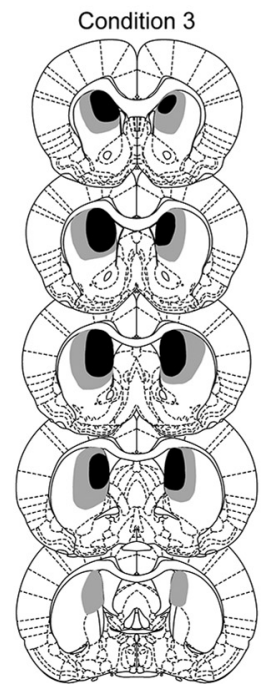

D
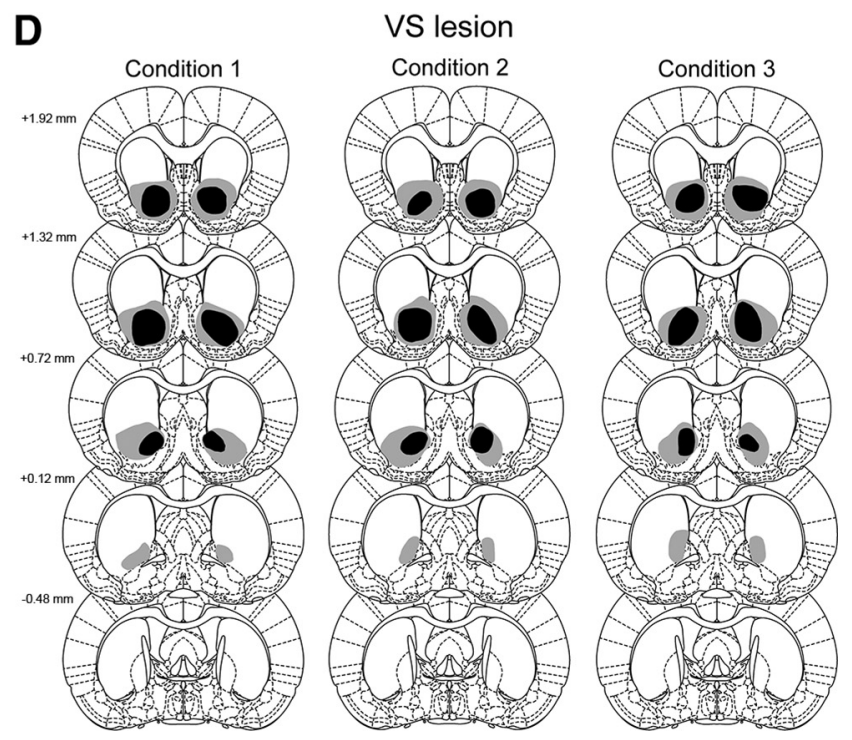

Figure 2. Histological verification of specific lesions of cholinergic interneurons. $\boldsymbol{A}$, Representative coronal sections of the rat striatum show intact NeuN staining but clear ablation of the cholinergic interneurons in ChAT staining in lesioned cases (DMS or VS). Scale bar, $1 \mathrm{~mm}$. $\boldsymbol{B}$, An example of a small nonspecific lesion indicated by a dashed area (NeuN) where there are sparse cells. $\boldsymbol{C}, \boldsymbol{D}$, The smallest (black) and largest cases (gray) of cholinergic interneuronal ablation in each group are drawn separately in three conditions. Distance from bregma is indicated to the left. The size of lesions in DMS ( $\boldsymbol{C}$ ) and VS (D) appears equivalent across conditions. LV, lateral ventricle; CC, corpus callosum; AC, anterior commissure.

(Fig. 3C; one-way ANOVA, $\left.F_{(2,51)}<1, p>0.05\right)$. Analyzing the number of never-reinforced errors showed a significant difference between groups (Fig. 3C; one-way ANOVA, $F_{(2,51)}=5.224$, $p=0.009$ ). Compared with the control, a significant decrease was found in both types of cholinergic lesions in DMS (Dunnett's, $p=0.007$ ) and VS (Dunnett's, $p=0.045$ ), particularly in the early phase of learning (Fig. $3 C$; one-way ANOVA, $F_{(2,51)}=$ 8.930, $p<0.001$; Dunnett's, DMS vs control: $p<0.001$; VS vs control: $p=0.019$ ) but not in the late phase of learning (one-way ANOVA, $\left.F_{(2,51)}<2, p>0.05\right)$.

These findings demonstrate that lesions of cholinergic interneurons in DMS affected strategy set-shifting, particularly when it required attending to the previously irrelevant stimulus (Fig. 3C, condition 3), in that an abnormal distribution of error types was evident. On the other hand, cholinergic ablation in VS had a specific influence on the set-shifting when a novel cue was introduced (Fig. $3 A$, condition 1), resulting in more perseverative errors during a shift.

Last, Figure 4 shows that the performance in retraining of the response strategy was not different between groups (Fig. 4; in all conditions: $F<1.2, p>0.05)$. Also, neither lesion had an effect on performance in reversal learning (Fig. 4; in all conditions: $F<$ $1.6, p>0.05)$. Comparisons of the number of perseverative and regressive errors during reversal learning revealed no statistically significant differences between groups (Fig. 4; in all conditions, $F<2.5, p>0.05)$. These results indicated that the lesions of the cholinergic interneurons did not affect retraining of a previously learned strategy and its reversal.

\section{Discussion}

We investigated the effect of a selective lesion of striatal cholinergic interneurons on set-shifting and reversal learning. We found that lesions of cholinergic interneurons in the DMS caused a significant impairment of learning after a shift that required attending to a previously irrelevant stimulus. This impairment was evident in an increase of the perseverative errors after the shift when animals attempted to find a new behavioral rule. There was an associated decrease in the number of never-reinforced errors, which was particularly evident at an early stage of learning, suggesting that the perseverative errors were made at the expense of exploration of alternative strategies (Floresco et al., 2008). In set-shifting requiring attention to a novel stimulus, lesions of the VS resulted in a significant increase of perseverative errors, implying that animals were unable to inhibit the use of a now invalid strategy and to facilitate exploration toward the novel cue. Neither of the lesions affected set-shift requiring attention to a pre- 


\section{A Condition 1}
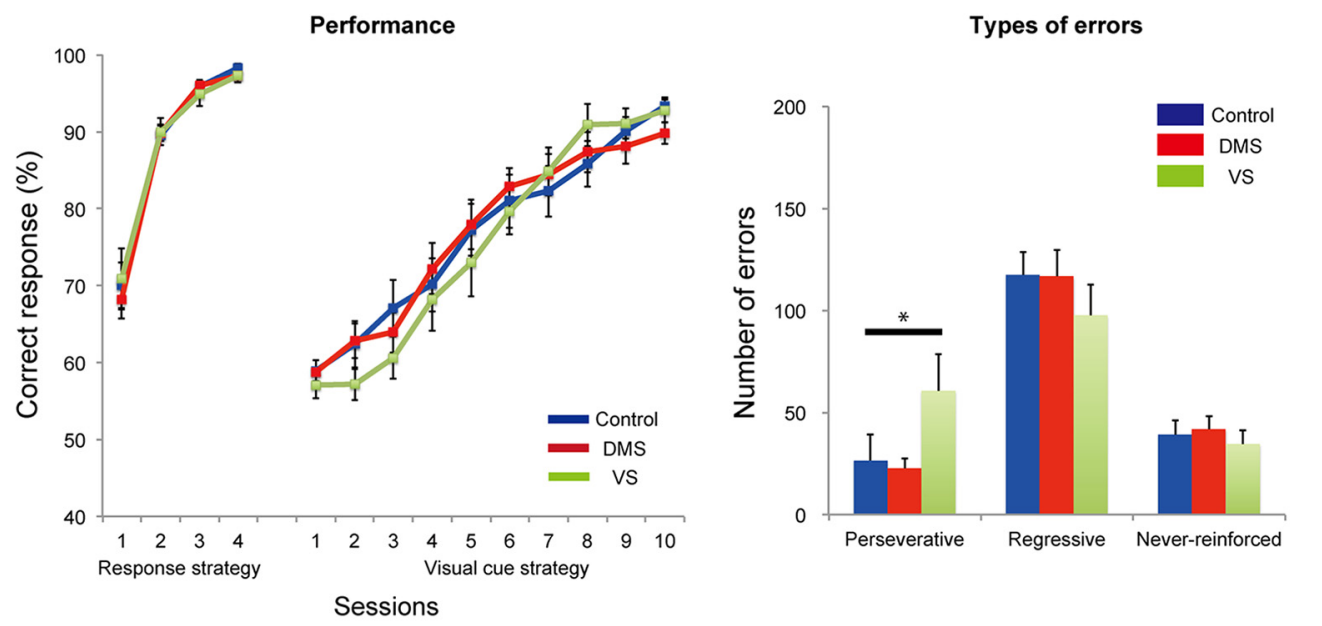

Early and late components

of never-reinforced errors

\section{B Condition 2}
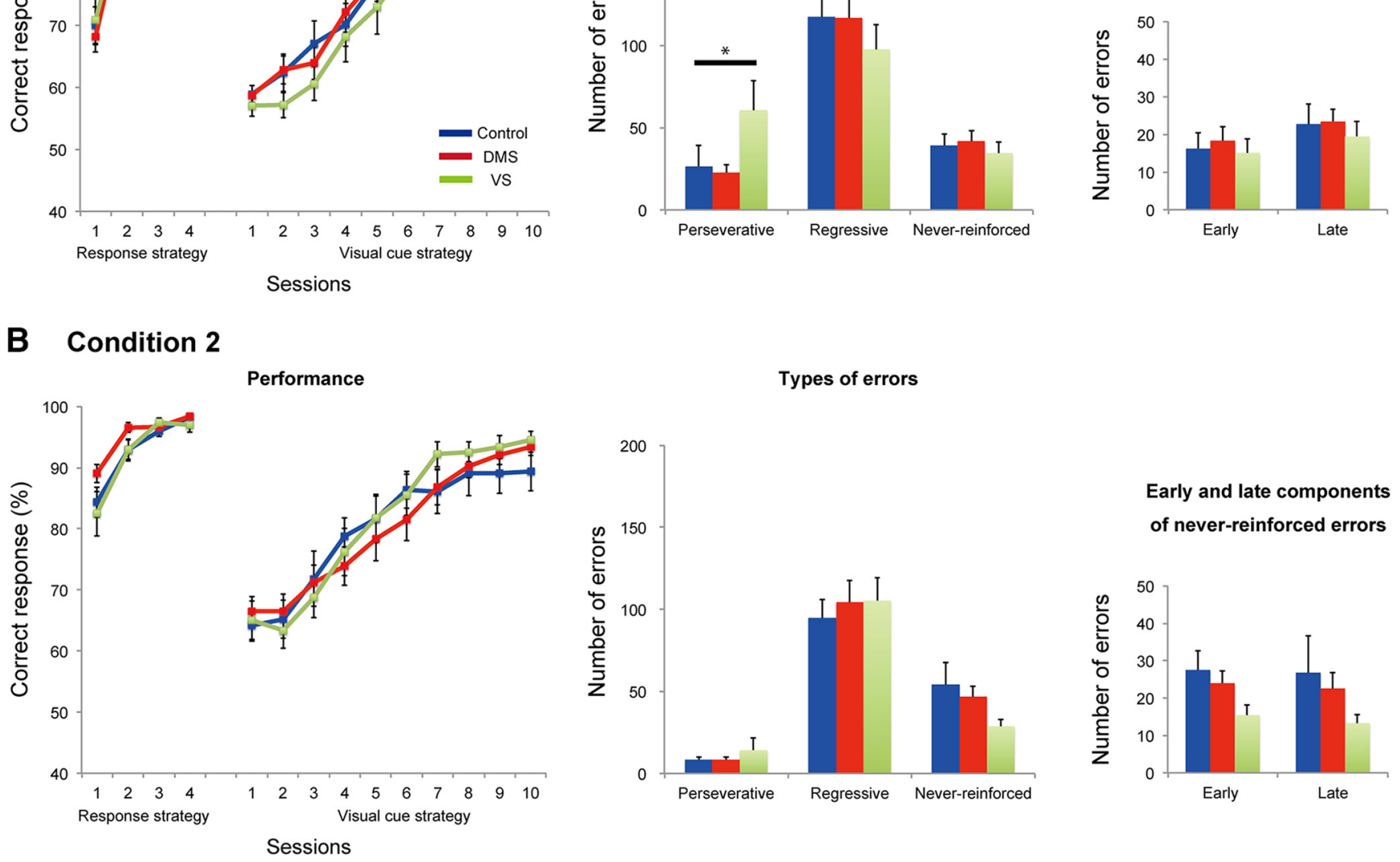

\section{Condition 3}
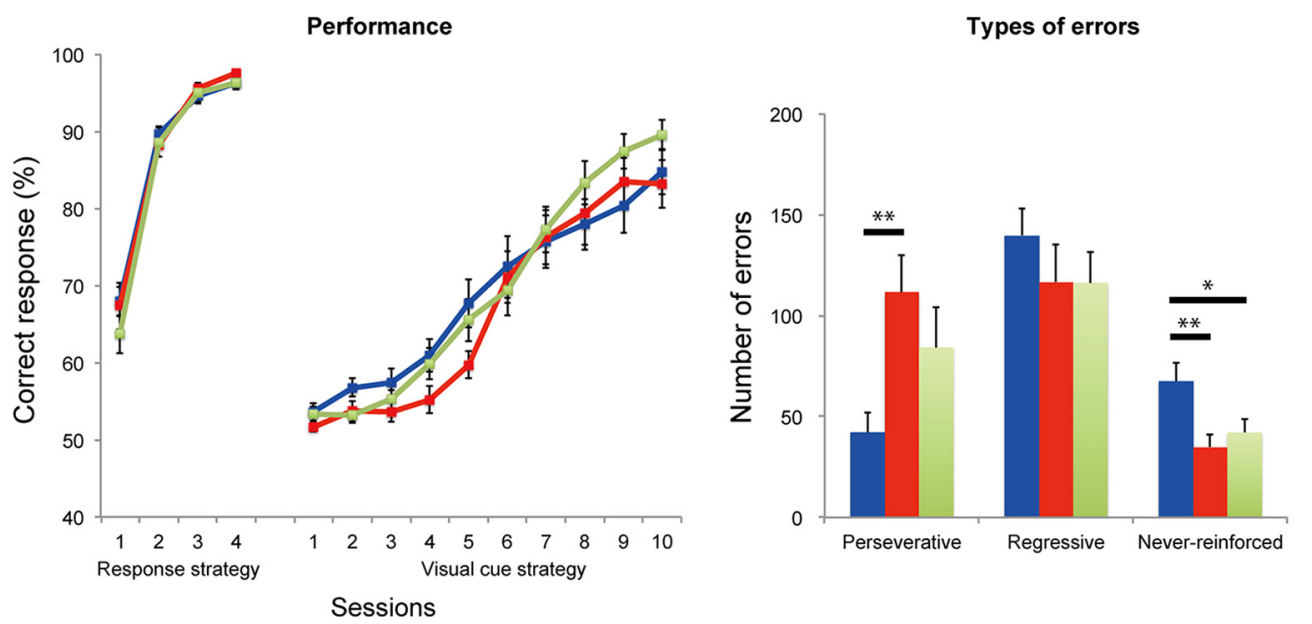

\section{Early and late components of never-reinforced errors}

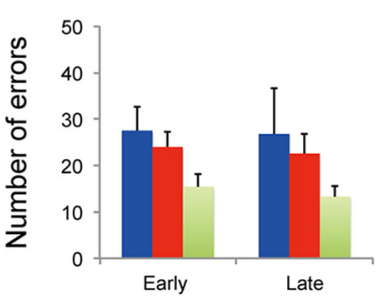

Early and late components of never-reinforced errors

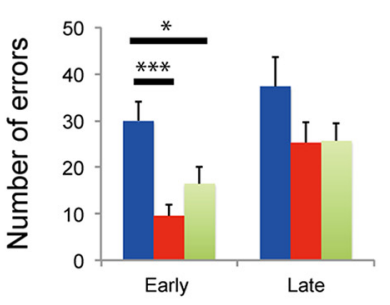

Figure 3. Behavioral performance and types of errors in strategy set-shifting. Percentage of correct responses in both response and visual cue strategy (left), types of errors committed over 10 sessions of visual cue strategy (middle), and early and late components of never-reinforced errors (right) are shown for each experimental condition. Set-shifting required attention to a novel stimulus $(\boldsymbol{A})$, to a previously relevant stimulus $(\boldsymbol{B})$, and to a previously irrelevant stimulus (C). Final group size is as follows: condition $1, n=16$ (control), $n=19$ (DMS), $n=14$ (VS); condition 2, $n=13$ (control), $n=18$ (DMS), $n=14$ (VS); condition 3, $n=21$ (control), $n=17$ (DMS), $n=16$ (VS). Data are shown as means \pm SEM. ${ }^{*} p<0.05$, ${ }^{* *} p<0.01$, and ${ }^{* * *} p<0.001$. 


\section{Condition 1}

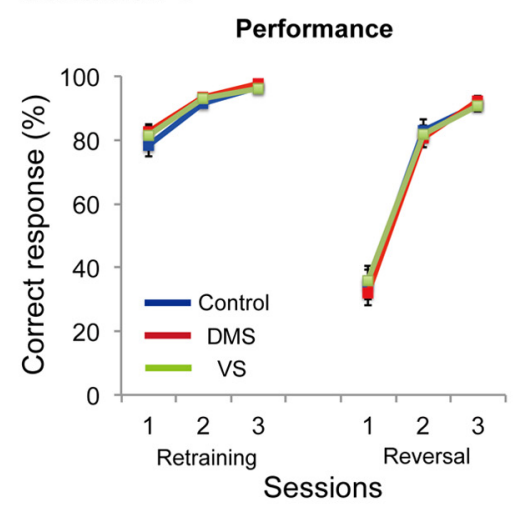

Condition 2

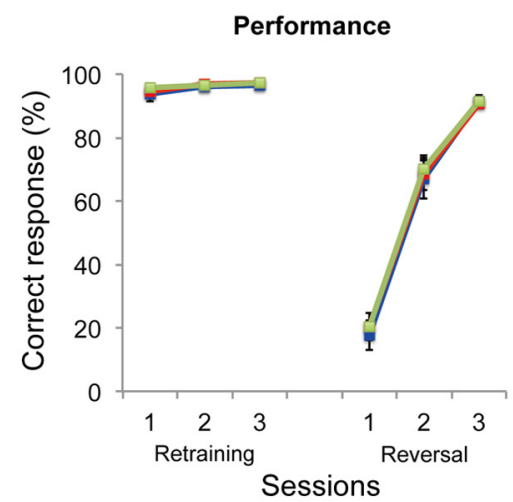

\section{Condition 3}

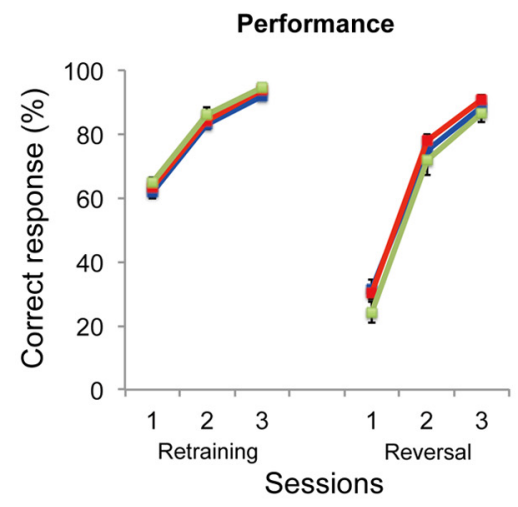

Types of errors

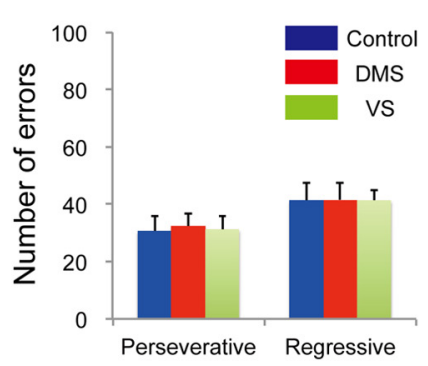

Types of errors

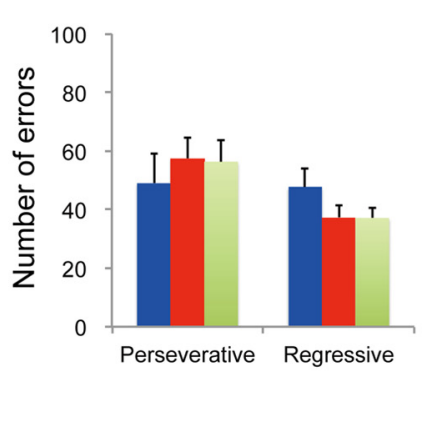

Types of errors

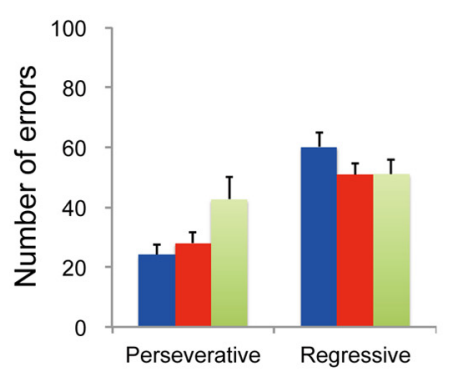

Figure 4. Behavioral performance and types of errors in retraining and reversal of the response strategy. Percentage of correct responses in retraining of the original response strategy and its reversal (left) and types of errors committed during reversal learning (right) are shown for each condition. Final group size is the same as Figure 3. Data are means \pm SEM.

tor antagonists (Ragozzino et al., 2002a; McCool et al., 2008) results from a lack of extrinsic cholinergic modulation by brainstem nuclei (Dautan et al., 2014), as opposed to the intrinsic cholinergic neurons (Okada et al., 2014). In agreement with the present findings, a previous study showed that loss of DMS cholinergic transmission did not affect reversal learning (Bradfield et al., 2013b). However, the same study showed that animals were unable to use the knowledge of reversed contingency when tested by a devaluation test. This more specific role of cholinergic interneurons in reversal learning was not assessed in the present study.

The present study focuses specifically on cholinergic function localized to the striatum, mediated by the cholinergic interneurons. The contribution of other cholinergic systems to attentional setshifting has been considered in previous studies. Generalized blockade of muscarinic cholinergic receptors induced by systemic injections of scopolamine disrupted extradimensional shifts but not initial learning (Chen et al., 2004). However, localized immunotoxin lesions of basal forebrain cholinergic fibers projecting to medial frontal cortex did not impair set-shifting (McGaughy et al., 2008). These findings are consistent with the proposal that cholinergic receptors outside of neocortex play an important role in regulating attentional shifts (Chen et al., 2004). The present findings extend these results by showing specifically that the intrinsic cholinergic neurons of the striatum play a crucial role in extradimensional shifts (condition 3).

Previous work has shown that the prefrontal cortex plays a role in inhibiting the use of a previously learned strategy (Ragozzino et al., 1999; Floresco et al., 2006b), consistent with the strong connectivity of the prefrontal cortex with the DMS and VS. The perseverative deficit we observed due to the specific cholinergic lesions was different from

viously relevant stimulus, retraining of the original response strategy, nor reversal of the original response. To our knowledge, this is the first study to demonstrate a specific role of striatal cholinergic interneurons in set-shifting, namely suppressing the use of an old strategy and promoting exploration of a new rule. Furthermore, this role is possibly dissociable between dorsomedial and ventral striatum depending on behavioral context.

We observed no effect of lesions of the cholinergic interneurons on reversal learning. However, in previous studies locally injected cholinergic antagonists have been found to impair reversal learning (Ragozzino et al., 2002a, 2003; McCool et al., 2008). In contrast, specific cholinergic interneuronal ablation has been reported to enhance learning of a spatial reversal task (Okada et al., 2014). It is possible that impaired reversal learning caused by muscarinic recep- the regressive deficit caused by injection of local anesthetic in the DMS or VS (Ragozzino et al., 2002b; Floresco et al., 2006a), a procedure that inactivates the principal neurons as well as the cholinergic interneurons. These findings are consistent with a model in which cholinergic interneurons are necessary to inhibit the use of a previously learned strategy and promote exploration, rather than maintain responding after switching to a new strategy. One possible physiological function of the cholinergic interneurons is inhibition of striatal projection neuron activity (Ding et al., 2010). Another is cholinergic modulation of dopamine (DA) release in the striatum. Recent studies suggest that DA release is triggered by synchronous activities of cholinergic interneurons in both dorsal (Threlfell et al., 2012) and ventral striatum (Cachope et al., 
2012) and such DA release is related to exploration (Rebec et al., 1996a, b).

If, as we propose, in set-shifting cholinergic interneurons suppress a now invalid strategy and facilitate exploration of a new strategy, then how can we explain the dissociation of VS and DMS findings? One possibility is that both findings result from a similar mechanism, but one that operates on different inputs and outputs. Unlike the DMS, the VS receives dense direct projections from hippocampus (Kelley and Domesick, 1982; Naber and Witter, 1998; Groenewegen et al., 1999; Voorn et al., 2004; Floresco, 2015), which plays a role in novelty detection (Knight, 1996; Lisman and Otmakhova, 2001; Ranganath and Rainer, 2003; VanElzakker et al., 2008; Mannella et al., 2013). For example, Mannella et al. (2013) proposed that the VS plays a role in biasing action selection based on the novelty of stimuli as detected by the hippocampus. Thus the VS is suitably situated to facilitate responses (potentially exploration) toward a novel stimulus away from the old rule. Conversely, we also showed that DMS cholinergic interneurons play a role when contingency of a stimulus changes. Bradfield et al. (2013a) suggested that cholinergic transmission in posterior DMS is important for learning about response-outcome contingency, whereas the anterior DMS is involved in a stimulus-outcome contingency. Our DMS lesions were more anterior than the posterior DMS lesions made by Bradfield et al. (2013b). Thus, our results are consistent with the suggested involvement of anterior DMS in set-shifting based on change in contingency of a stimulus.

Since novelty itself has motivational value (Mannella et al., 2013), responses to novel stimuli may entail Pavlovian approach behavior controlled by the VS (Di Ciano et al., 2001; Floresco, 2015). Yet, importantly, the fact that VS cholinergic lesions had no effect on initial learning in any condition suggests that this role cannot be generalized; rather, it is specialized to an attentional/ directional shift to the novel stimulus by which a switch of strategies is accomplished. In contrast, the absence of effect of DMS lesions in condition 1 could be due to the intact ventral cholinergic system. As noted above, condition 1 might involve VSdependent response to novelty (Wittmann et al., 2008; Mannella et al., 2013), such that the intact VS overrides the effect of the DMS cholinergic loss.

Lack of significant effect of VS lesions on perseveration in condition 3 might also be due to nonselectivity of the lesions for core and shell subdivisions, which play dissociable roles (Weiner, 2003; Floresco et al., 2006a; Schiller et al., 2006; Dalton et al., 2014). Thus, the effect of cholinergic lesions could be canceled out. Note, however, that both DMS and VS lesions led to a decrease of never-reinforced errors in condition 3 , suggesting that not only the dorsomedial but also the ventral striatal cholinergic system helps facilitate exploration over perseveration in this context.

Consistent with the present findings, other evidence suggests that there is a cholinergic mechanism for inhibition of a previously learned response in the striatum. Lee et al. (2006) recorded putative cholinergic interneurons in monkeys performing a go/ no-go task that involved action initiation and inhibition. Cholinergic interneurons showed burst firing activity when a monkey correctly withheld his movement in no-go trials. Lee et al. proposed that cholinergic interneurons suppress planned movements by inhibiting striatal projection neurons. It has also been shown that burst firing of cholinergic interneurons caused by thalamic inputs transiently suppresses cortical drive to striatal spiny projection neurons (Ding et al., 2010), which Ding et al. proposed as a possible mechanism for shift of attention and re- direction of behavior. By such mechanisms, burst firing of cholinergic interneurons may suppress a previously correct but now incorrect strategy, and enable a search for an alternative strategy. Loss of this mechanism may explain the increase of perseverative errors after the shift when animals attempted to find a new behavioral rule, and the associated impairment of exploratory behavior in the present study.

\section{References}

Aosaki T, Graybiel AM, Kimura M (1994) Effect of the nigrostriatal dopamine system on acquired neural responses in the striatum of behaving monkeys. Science 265:412-415. CrossRef Medline

Aosaki T, Kimura M, Graybiel AM (1995) Temporal and spatial characteristics of tonically active neurons of the primate's striatum. J Neurophysiol 73:1234-1252. Medline

Apicella P (2007) Leading tonically active neurons of the striatum from reward detection to context recognition. Trends Neurosci 30:299-306. CrossRef Medline

Bradfield LA, Hart G, Balleine BW (2013a) The role of the anterior, mediodorsal, and parafascicular thalamus in instrumental conditioning. Front Syst Neurosci 7:51. CrossRef Medline

Bradfield LA, Bertran-Gonzalez J, Chieng B, Balleine BW (2013b) The thalamostriatal pathway and cholinergic control of goal-directed action: interlacing new with existing learning in the striatum. Neuron 79:153166. CrossRef Medline

Brown HD, Baker PM, Ragozzino ME (2010) The parafascicular thalamic nucleus concomitantly influences behavioral flexibility and dorsomedial striatal acetylcholine output in rats. J Neurosci 30:14390-14398. CrossRef Medline

Cachope R, Mateo Y, Mathur BN, Irving J, Wang HL, Morales M, Lovinger DM, Cheer JF (2012) Selective activation of cholinergic interneurons enhances accumbal phasic dopamine release: setting the tone for reward processing. Cell Rep 2:33-41. CrossRef Medline

Castañé A, Theobald DE, Robbins TW (2010) Selective lesions of the dorsomedial striatum impair serial spatial reversal learning in rats. Behav Brain Res 210:74-83. CrossRef Medline

Chen KC, Baxter MG, Rodefer JS (2004) Central blockade of muscarinic cholinergic receptors disrupts affective and attentional set-shifting. Eur J Neurosci 20:1081-1088. CrossRef Medline

Dalton GL, Phillips AG, Floresco SB (2014) Preferential involvement by nucleus accumbens shell in mediating probabilistic learning and reversal shifts. J Neurosci 34:4618-4626. CrossRef Medline

Dautan D, Huerta-Ocampo I, Witten IB, Deisseroth K, Bolam JP, Gerdjikov T, Mena-Segovia J (2014) A major external source of cholinergic innervation of the striatum and nucleus accumbens originates in the brainstem. J Neurosci 34:4509-4518. CrossRef Medline

Dias R, Aggleton JP (2000) Effects of selective excitotoxic prefrontal lesions on acquisition of nonmatching- and matching-to-place in the T-maze in the rat: differential involvement of the prelimbic-infralimbic and anterior cingulate cortices in providing behavioural flexibility. Eur J Neurosci 12: 4457-4466. CrossRef Medline

Dias R, Robbins TW, Roberts AC (1996) Dissociation in prefrontal cortex of affective and attentional shifts. Nature 380:69-72. CrossRef Medline

Dias R, Robbins TW, Roberts AC (1997) Dissociable forms of inhibitory control within prefrontal cortex with an analog of the Wisconsin Card Sort Test: restriction to novel situations and independence from "OnLine" processing. J Neurosci 17:9285-9297. Medline

Di Ciano P, Cardinal RN, Cowell RA, Little SJ, Everitt BJ (2001) Differential involvement of NMDA, AMPA/Kainate, and dopamine receptors in the nucleus accumbens core in the acquisition and performance of pavlovian approach behavior. J Neurosci 21:9471-9477. Medline

Ding JB, Guzman JN, Peterson JD, Goldberg JA, Surmeier DJ (2010) Thalamic gating of corticostriatal signaling by cholinergic interneurons. Neuron 67:294-307. CrossRef Medline

Floresco SB (2015) The nucleus accumbens: an interface between cognition, emotion, and action. Annu Rev Psychol 66:25-52. CrossRef Medline

Floresco SB, Ghods-Sharifi S, Vexelman C, Magyar O (2006a) Dissociable roles for the nucleus accumbens core and shell in regulating set shifting. J Neurosci 26:2449-2457. CrossRef Medline

Floresco SB, Magyar O, Ghods-Sharifi S, Vexelman C, Tse MT (2006b) Multiple dopamine receptor subtypes in the medial prefrontal cortex of 
the rat regulate set-shifting. Neuropsychopharmacology 31:297-309. CrossRef Medline

Floresco SB, Block AE, Tse MT (2008) Inactivation of the medial prefrontal cortex of the rat impairs strategy set-shifting, but not reversal learning, using a novel, automated procedure. Behav Brain Res 190:85-96. CrossRef Medline

Graybiel AM, Aosaki T, Flaherty AW, Kimura M (1994) The basal ganglia and adaptive motor control. Science 265:1826-1831. CrossRef Medline

Groenewegen H, Mulder A, Beijer AVJ, Wright CI, Lopes da Silva F, Pennartz CMA (1999) Hippocampal and amygdaloid interactions in the nucleus accumbens. Psychobiology 27:149-164.

Hunt PR, Aggleton JP (1998) Neurotoxic lesions of the dorsomedial thalamus impair the acquisition but not the performance of delayed matching to place by rats: a deficit in shifting response rules. J Neurosci 18:1004510052. Medline

Jones B, Mishkin M (1972) Limbic lesions and the problem of stimulusReinforcement associations. Exp Neurol 36:362-377. CrossRef Medline

Kelley AE, Domesick VB (1982) The distribution of the projection from the hippocampal formation to the nucleus accumbens in the rat: an anterograde and retrograde-horseradish peroxidase study. Neuroscience 7:2321-2335. CrossRef Medline

Kimura M, Rajkowski J, Evarts E (1984) Tonically discharging putamen neurons exhibit set-dependent responses. Proc Natl Acad Sci U S A 81: 4998-5001. CrossRef Medline

Knight R (1996) Contribution of human hippocampal region to novelty detection. Nature 383:256-259. CrossRef Medline

Laplante F, Lappi DA, Sullivan RM (2011) Cholinergic depletion in the nucleus accumbens: effects on amphetamine response and sensorimotor gating. Prog Neuropsychopharmacol Biol Psychiatry 35:501-509. CrossRef Medline

Lee IH, Seitz AR, Assad JA (2006) Activity of tonically active neurons in the monkey putamen during initiation and withholding of movement. J Neurophysiol 95:2391-2403. CrossRef Medline

Lisman JE, Otmakhova NA (2001) Storage, recall, and novelty detection of sequences by the hippocampus: elaborating on the SOCRATIC model to account for normal and aberrant effects of dopamine. Hippocampus 11: 551-568. CrossRef Medline

Mannella F, Gurney K, Baldassarre G (2013) The nucleus accumbens as a nexus between values and goals in goal-directed behaviour: a review and a new hypothesis. Front Behav Neurosci 7:135. CrossRef Medline

McCool MF, Patel S, Talati R, Ragozzino ME (2008) Differential involvement of M1-type and M4-type muscarinic cholinergic receptors in the dorsomedial striatum in task switching. Neurobiol Learn Mem 89:114124. CrossRef Medline

McGaughy J, Ross RS, Eichenbaum H (2008) Noradrenergic, but not cholinergic, deafferentation of prefrontal cortex impairs attentional setshifting. Neuroscience 153:63-71. CrossRef Medline

Miller EK (2000) The prefrontal cortex and cognitive control. Nat Rev Neurosci 1:59-65. CrossRef Medline

Morris G, Arkadir D, Nevet A, Vaadia E, Bergman H (2004) Coincident but distinct messages of midbrain dopamine and striatal tonically active neurons. Neuron 43:133-143. CrossRef Medline

Naber PA, Witter MP (1998) Subicular efferents are organized mostly as parallel projections: a double-labeling, retrograde-tracing study in the rat. J Comp Neurol 393:284-297. CrossRef Medline

Nicolle MM, Baxter MG (2003) Glutamate receptor binding in the frontal cortex and dorsal striatum of aged rats with impaired attentional setshifting. Eur J Neurosci 18:3335-3342. CrossRef Medline

Okada K, Nishizawa K, Fukabori R, Kai N, Shiota A, Ueda M, Tsutsui Y, Sakata S, Matsushita N, Kobayashi K (2014) Enhanced flexibility of place discrimination learning by targeting striatal cholinergic interneurons. Nat Commun 5:3778. CrossRef Medline

Paxinos G, Watson C (2004) The rat brain in stereotaxic coordinates. San Diego: Elsevier Academic.

Pisa M, Cyr J (1990) Regionally selective roles of the rat's striatum in modality-specific discrimination learning and forelimb reaching. Behav Brain Res 37:281-292. CrossRef Medline

Ragozzino ME (2003) Acetylcholine actions in the dorsomedial striatum support the flexible shifting of response patterns. Neurobiol Learn Mem 80:257-267. CrossRef Medline

Ragozzino ME, Detrick S, Kesner RP (1999) Involvement of the prelimbicinfralimbic areas of the rodent prefrontal cortex in behavioral flexibility for place and response learning. J Neurosci 19:4585-4594. Medline

Ragozzino ME, Jih J, Tzavos A (2002a) Involvement of the dorsomedial striatum in behavioral flexibility: role of muscarinic cholinergic receptors. Brain Res 953:205-214. CrossRef Medline

Ragozzino ME, Ragozzino KE, Mizumori SJ, Kesner RP (2002b) Role of the dorsomedial striatum in behavioral flexibility for response and visual cue discrimination learning. Behav Neurosci 116:105-115. CrossRef Medline

Ranganath C, Rainer G (2003) Neural mechanisms for detecting and remembering novel events. Nat Rev Neurosci 4:193-202. CrossRef Medline

Ravel S, Sardo P, Legallet E, Apicella P (2006) Influence of spatial Information on responses of tonically active neurons in the monkey striatum. J Neurophysiol 95:2975-2986. CrossRef Medline

Rebec GV, Grabner CP, Johnson M, Pierce RC, Bardo MT (1997a) Transient increases in catecholaminergic activity in medial prefrontal cortex and nucleus accumbens shell during novelty. Neuroscience 76:707-714. CrossRef Medline

Rebec GV, Christensen JR, Guerra C, Bardo MT (1997b) Regional and temporal differences in real-time dopamine efflux in the nucleus accumbens during free-choice novelty. Brain Res 776:61-67. CrossRef Medline

Schiller D, Zuckerman L, Weiner I (2006) Abnormally persistent latent inhibition induced by lesions to the nucleus accumbens core, basolateral amygdala and orbitofrontal cortex is reversed by clozapine but not by haloperidol. J Psychiatr Res 40:167-177. CrossRef Medline

Threlfell S, Lalic T, Platt NJ, Jennings KA, Deisseroth K, Cragg SJ (2012) Striatal dopamine release is triggered by synchronized activity in cholinergic interneurons. Neuron 75:58-64. CrossRef Medline

VanElzakker M, Fevurly RD, Breindel T, Spencer RL (2008) Environmental novelty is associated with a selective increase in Fos expression in the output elements of the hippocampal formation and the perirhinal cortex. Learn Mem 15:899-908. CrossRef Medline

Voorn P, Vanderschuren LJ, Groenewegen HJ, Robbins TW, Pennartz CM (2004) Putting a spin on the dorsal-ventral divide of the striatum. Trends Neurosci 27:468-474. CrossRef Medline

Weiner I (2003) The "two-headed" latent inhibition model of schizophrenia: modeling positive and negative symptoms and their treatment. Psychopharmacology 169:257-297. CrossRef Medline

Wittmann BC, Daw ND, Seymour B, Dolan RJ (2008) Striatal activity underlies novelty-based choice in humans. Neuron 58:967-973. CrossRef Medline 